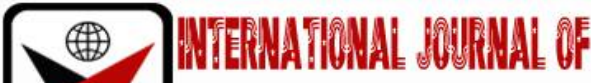

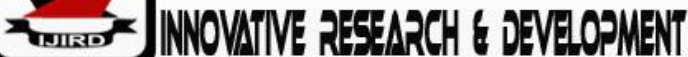

ISSN 2278 - 0211 (Online)

\section{Construction of Feminine Identity through Metaphor in Facebook Discourses}

\begin{tabular}{c} 
Gerald Otieno Njura \\
Post Graduate Scholar, Department of Languages, Linguistics and Literature, \\
Rongo University, Kenya \\
Dr. Pamela Anyango Oloo \\
Senior Lecturer, Department of Linguistics, Maseno University, Kenya \\
Dr. Eric Omondi Odero \\
Lecturer, Department of Languages, Linguistics and Literature, Rongo University, Kenya \\
\hline
\end{tabular}

\begin{abstract}
:
One of the ways through which people construct their identities and others' identities is through use of conceptual metaphors. Conceptual metaphors are not just elements of language but are elements of thought as well and as such they both reflect the inner feelings of language users and describe the world. The purpose of this study was to interpret how feminine identities are constructed through use of metaphors among Kenyan Facebook users. The study was premised on the Conceptual Metaphor Theory (Kovecses, 2008) a development of Lakoff and Johnson's (1980) work on metaphors. The study population comprised of sixty-five metaphors collected from 100 articles that were posted on Facebook between January, 20017 and May, 2018. Purposive sampling technique was used to select the texts with required metaphorical expressions and saturated sampling technique was employed to get adequate linguistic metaphors for analysis. The study reported that Kenyan females are mostly negatively constructed by the metaphors. They are portrayed as evil and dangerous beings who do not hesitant to cause harm to their male counterparts. They are represented as dangerous and exploitative.
\end{abstract}

Keywords: Metaphor, source-domain, target-domain, cross-domain mappings

\section{Introduction}

This article explored the way members of the Facebook speech community in Kenya construct feminine identity through the discourses they engage in. Bloor \& Bloor (2013) define identity as the way people see themselves in relation to others. This means that identity is social. Femininity, on the other hand, is a dimension of gender which refers to an individual's identity in terms of femaleness. Like any other identity, femininity is constructed by the society with the help of different individuals, groups and social institutions, including Social Networking Sites (SNS) such as Facebook and language is the basic tool used in the construction of identities (Ali and Khan, 2012). One language element used in the construction of identities generally and feminine identity in particular is metaphor. Studies have argued that metaphors are not just mere rhetorical ornaments, but a powerful means by which individuals make sense of themselves and the world around them (Zubair, 2007). Lakoff and Johnson (1980) explain that metaphors are not just a matter of language; they actually control the human thought process. The human conceptual system is metaphorically structured and defined (Lakoff and Johnson, 1980).

This study is born out of the raging debate about the welfare of the boychild in Kenya. This debate is not only limited to mainstream media, but also in various Social Networking Sites including Facebook. The trajectory of the debate seems to suggest that the Kenyan boy child neglected and vulnerable. Oneof the reasons for the neglect of the boy-child, the debate seems to suggest, is the long-standing focus on empowering the girlchild by both government and nongovernment agencies. The empowered girl-child has now become a challenge to the boy-child and the debate also suggests that the boy child is vulnerable to exploitation by the girl child in Kenya.

Previous studies on gender constructions and gender identities in Kenya tended to focus on the mainstream media such as television (Mokamba-Kimuna, 2003), newspapers (Nduva, 2016; Muthoni and Ukaiko), and radio (Omollo, Tchai and Ukaiko, 2015) and very little was done on the social media platforms. It is for this reason that the study chose the social media platform, Facebook, to interpret ways through feminine identities are constructed by use of metaphors. Another reason for the choice of Facebook is because of the age of the majority of its users who are youth and gender being dynamic, the study sought to explore how this majorly youthful audience understand the concept of femininity. 


\section{Literature Review}

This section identified key literature that explains the gender relations status in Kenya, the conceptualization of metaphor, key studies that have impact on the current study and theoretical understanding that underpin this study.

\subsection{Gender Relations Status in Kenya}

Most communities in Kenya are patriarchal in nature thereby endowing men and boys with numerous rights including both the right to education and the right to property inheritance. The patriarchal system among Kenyan communities has been blamed for the myriad challenges that Kenyan women and girls have faced for a long. Among these challenges include early marriages, school drop-outs, Female Genital Mutilation (FGM), lack of economic independence and lack of political representation. Scholars such as Munyao (2013) have identified four main factors that deter women from achieving their right to gender equality: ethnic differences/ rivalry; effects of colonialism; autocratic leadership; and the desire to preserve cultural norms and practices.

This scenario was first questioned and challenged by the Beijing conference held in China in 1995 whose main objective was to strategize on measures to ensure women's equal access to and full participation in power structures and decision making (NGEC, 2015). The conference envisaged that empowering women, giving women more autonomy, improving their social, economic and political status was essential for the achievement of both transparent and accountable governance and administration for sustainable development in all spheres of life.

Since then, the Kenyan government, NGOs and other international organizations embarked on empowering women and the girl-child. This journey got a shot in the arm with the promulgation of the Kenya, 2010 constitution. Among other things, the constitution recognized women's rights as human rights. The 2010 Kenyan constitution recognizes dignity, economic social and cultural rights including the right to education, housing and right to health including reproductive health care. The principle of equality and non-discrimination is established as a core value in leadership. The implementation of this constitution has seen more women get elected and/or nominated into political, governance and administrative positions. Unfortunately, these noble gestures have also created a perception among some Kenyans that in the spirit of empowerment women and girls, boys and men are being marginalized. This feeling of marginalization of men and boys has generated heated discourse in both mainstream and social media platforms. This study aims to assess how metaphors and similes employed in this debate portray women.

\subsection{Metaphor}

A lot of scholars have attempted to define the concept metaphor. Shaw (1972) defines metaphor as 'a figure of speech in which a word or phrase is applied to a person, idea or object to which it is not literally applicable'. Newmark (1988) define metaphor as 'any figurative expression; the transferred sense of a physical word; the personification of an abstraction; the application of a word and collocation to what it doesn't literally denote'. These definitions are more literature than linguistics. From a linguistics point of view, Deignan (2005) defines metaphor as 'a word or expression that I used to talk about an entity or quality other than that referred to by its core or more basic meaning'. This study adopts Lakoff \& Johnson's (1980) definition that conceptualizes metaphors as 'understanding and experiencing one kind of thing in terms of another'. This definition is adopted as it captures the aim of the study which is to understand what items, or things are used in the understanding of women. According to Lakoff \& Turner (1989) is created by mapping two unrelated concepts onto each other, thereby conceptualizing one concept (the target) in terms of another (the source). This study aimed to assess how women (the target) are conceptualized by members of Facebook by drawing on what kinds of items (the source). Metaphors, as argued by Ahmed (2018) are a rich resource from which individuals may draw on in the discursive construction of self-image.

\subsection{Gender Studies}

Unger (1979) defines gender as 'a label that is associated with non-physiological characteristics that societies or specific cultures assign to men and women'. Gender is understood as the responsibilities that men and women have in particular societies. Unlike sex which is biological, gender is social and is never static. People display and perform gender differently depending on context. People perform gender through their actions and by the way they speak. It is in this sense that the study is interested in understanding how Facebook discourse community do femininity. Feldman (1996) identifies three kinds of gender: masculine; feminine and neuter, but this study only focused on femininity.

Quite a number of studies have been conducted in Kenya on how people construct gender in various discourse genres such as proverbs (Ndun'go,1998), advertisements (Mandillah, 2006), political discourse (Ndambuki, 2010), the bible (Mwaniki, 2011), songs (Anyango, 2014), literary texts (Mulila-Matei, 2014), narratives (Wanjiru \&Kabiru, 2015), radio talk shows (Omollo, Tchai\&Kitetu, 2015) and newspapers (Muthoni \&Ukaiko, 2016). Despite the richness in diversity, there appears to be a lack of focus on the social media despite its widespread and popularity amongst the youth. This study focuses on how the Facebook users construct femininity.

\subsection{Discourse, Ideology and Gender}

Discourse is understood as 'a system of statements which cohere around common meanings and values', (Coates, Jennifer1996. p. 239). When we talk about discourse in this study, we are referring to the ideas, values, beliefs and notions that that are communicated by the discussions in Facebook on the roles, traits and characteristics of women and girls. Discourse plays a major role in constructing or structuring our experience and discourse.

One major claim of Critical Discourse Analysis is that it is constitutive; it constitutes society and culture and is in return constituted by society and culture (Fairclough \&Wodak, 1997). Discourse constitutes situations, objects of 
knowledge and the social identities of people. It also constitutes relationships between people and groups of people in society. When Fairclough and Wodak claim that discourse is constitutive, they mean that discourse can be used to sustain and reproduce status quo, for instance, discourse can be used to sustain domination of the masculine gender over the feminine gender in patriarchal societies and on the flip side, discourse can also be used to challenge and transform status quo where discourse is used to challenge and transform domination of the masculine gender over the feminine gender.

What links discourse and gender are the concept of ideology. Van Dijk (2000) defines ideology as 'as a special form of cognition shared by social groups. Ideologies thus form the basis of the social representations and practices of group members, including their discourse, which at the same time serves as the means of ideological production, reproduction and challenge.

\subsection{Theoretical Framework}

Analysis and interpretation of data in this study was premised on Conceptual Metaphor Theory (Kovecses, 2008), a theory that was started with George Lakoff and Mark Johnson's book, Metaphors We Live By (1980). This theory views metaphors not simply as ornamental devices in language, but as conceptual tools for structuring, restructuring and even creating reality. In this framework conceptual metaphors are defined as 'understanding one domain of experience (that is typically abstract) in terms of another (that is typically concrete)' where conceptual metaphors are captured both as a process and a product (Kovecses, 2008). The tenets of the theory, according to Kovecses, (2008) are: metaphors are all pervasive, meaning that they are likely to be found in all instances of language use; there is systematic mappings between two conceptual domains, to mean that elements and relations between them are said to be mapped from one domain (source domain) onto the other domain (target domain); mappings are from concrete domains to abstract domains, that is, the source domain is always concrete while the target domain is always abstract and finally that metaphors primarily occurs in thought with the implication that metaphors do not only reside in language but also in thought. As a result, we use metaphors not only to speak about certain aspects of the world, but also to think about them. For instance, in the conceptual metaphor WOMEN ARE PARASITES, conceptual metaphor theory perceives the behaviour of parasites (the source domain) to metaphorically understand the women (target domain). The following cross-domain mappings explain the metaphorical expression:

\begin{tabular}{|c|c|}
\hline Source Domain (Parasites) & Target Domain (Women) \\
\hline Insects & Females \\
Hosts & Males \\
Suck host's blood & Dependency \\
Host's deteriorating health & Status of men in Kenya \\
\hline
\end{tabular}

Table 1

Here insects are mapped onto the Kenyan females, the host are the Kenyan males, the insects' behaviour of blood sucking is mapped onto the Kenyan women's behaviour and the end-result, which is the hosts' deteriorating health is mapped onto the financial status of Kenyan men. Analysis of this kind revealed the identities of Kenyan females as discussed in conversations carried out on Facebook Groups in Kenya.

\section{Statement of the Problem}

Much discourse and pragmatic studies on gender construction in Kenya has tended to focus on mainstream media such as a television, radio, and newspapers. Little attention has been paid to how the social media in Kenya can be used to represent women through metaphor. Metaphors form a big part of our conceptual systems, in terms of which we both think and act. Analysis of metaphors was aimed at revealing how Facebook users- which presently is the second largest social media platform in Kenya with an audience that is majorly youthful (26-45-year-olds)- think of, understand and act toward women and girls. In this study I examined the many complex and often subtle ways in which some Facebook users used metaphors to construct feminine gender in Kenya.

\section{Methodology}

This study employed a descriptive qualitative research design as it focused on a description, analysis and explanation of the metaphors used in the Facebook discourses with the aim of showing the identity construction strategies used in representing women and girls. Three Facebook groups were purposively identified by the researcher as key sources of data. The Facebook groups are: Buyer Beware; Save the Boy-child; Cyprian Nyakundi Group. Data for this study was collected from 100texts posted on various dates and were available on various Facebook groups. This choice was deliberate since the researcher believed that the discourse community in Facebook is diverse enough to provide valid data that is able to answer the research questions.

The selection of texts for analysis was done in five stages. First, the researcher did an electronic search on Facebook for information about postings and comments concerning girl-child. Secondly, the researcher listed the body of relevant texts identified through electronic searches as meeting the study criteria. Thirdly, the researcher saved and printed the identified documents and read them in full for general understanding. This was followed by a critical reading of the texts from the perspective of intertextual relations (Fairclough, 1995) to establish the semantic relations and intertextual links among the texts. This was done to help the researcher deepen his understanding of the social practices that underlie the context of the study. Finally, texts or sections of texts that contained metaphors and similes reflecting feminine /identities were selected for analysis. 
In terms of relevant metaphor identification, Preglejaz' Group's (2007) Metaphor Identification Procedures was used. The procedure is outlined below;

- $\quad$ Read the entire text text-discourse to establish a general understanding of the meaning

- Determine the lexical units in the text-discourse.

- For each lexical unit in the text, establish its meaning in context, that is, how it applies to an entity, relation, or attribute in the situation evoked by the text (contextual meaning). Take into account what comes before and after the lexical unit.

- For each lexical unit, determine if it has a more basic contemporary meaning in other contexts than the one in the given context.

- If the lexical unit has a more basic current-contemporary meaning in other contexts than the given context, decide whether the contextual meaning contrasts with the basic meaning but can be understood in comparison with it.

- If yes, mark the lexical unit as metaphorical. (Group, 2007, p.3)

\section{Data Presentation, Analysis and Discussion}

This section presents the data that was collected from the data sources, analyses the metaphors by classifying them in terms of their source domains and discusses the findings with regards to prior studies on the construction of femininity by various authors.

\subsection{Data Presentation and Analysis}

Out of the one hundred texts that were collected for analysis in this study, sixty-five metaphors were identified as describing women and/or actions of women. The analysis of data identified eight strands of conceptualizations of the woman in these metaphors and this is represented in the table below;

\begin{tabular}{|c|c|c|}
\hline No. & Conceptual Metaphor & Frequency \\
\hline 1 & Commodity & 16 \\
\hline 2 & Object & 14 \\
\hline 3 & Animal & 13 \\
\hline 4 & Terrorist & 07 \\
\hline 5 & Syllabus & 05 \\
\hline 6 & Mass media & 04 \\
\hline 7 & Prisoner & 04 \\
\hline 8 & Food & 03 \\
\hline & Total & 65 \\
\hline
\end{tabular}

Table 2: Metaphoric Conceptualizations of Women

As evident from the table above, the Facebook discourses on women used metaphors drawn from various source domains such as; commodities, objects, animals, terrorists, syllabus, mass media, prisoners and food. The section below delves into the analysis of each domain and provides relevant examples.

\subsubsection{Women as Commodities}

The Oxford Dictionary of Current English (2006) defines a commodity as 'a raw material or agricultural product that can be bought and sold'. Analysis of our data took the idea that conceptualization of women as something/someone with a price tag, can be bought and sold, depreciates, or appreciates amounted to constructing women's identity as commodities. Our analysis realized that majority of the metaphors used to describe women conceptualized them in terms of commodities. For example;

- Women are naturally expensive. So, choose the bitch in your price range and stay in your lane

- Her price tag is so high until any man who admires her must accept bankruptcy as his next destination.

- After their product value diminishes, the same woman now heads back to their 'home-areas' in those satellite towns.

- The shelf-life of a woman is very short. If they don't get their shit together, then the effects are severe, consequences dire.

- Why is pussy so expensive, yet women are the majority in the country? Why should a product which is inflated in the market, still be commanding premium price? Who conditioned Kenyan men to discard empirical evidence and invest in vanity?

- $\quad$ Kenyan Women Modified Bride Price Formula for 2018

Real Bride price $=$ Asking Bride Price

No. of men slept with +1

- Women slut-shame each other, especially with those with diminished sexual market value.

The examples 1-7 of metaphors used to conceptualize women above represent them as commodities in a market, or in a shop that with men being the customers that buy them. Women are constructed as having a price tag/ price range, she is expensive, her market value diminishes, she has a shelf-life, and she is referred to as an inflated product in the market. This construction of women reduces them to the level of commodities and not human beings with dignity. 


\subsubsection{Women as Objects}

In the words of Van Leeuwen (2006 p. 46) objectivation 'occurs when social actors are represented by means of reference to a place or thing closely associated either with their person or with the action in which they are represented as being engaged'. In objectivation, women are represented through a feature or a thing, meaning that they are reduced to this feature or thing. Our analysis identified the following examples;

- Most likely the thirsty bitches coaxed the boys to visit them and extinguish the fire.

- Ain't no way a new-money niggre will tie himself down with a tired beat-up pussy.

- Women over 27 years don't have dates. They conduct auditions. Because of being banged by many dicks in their formative days, they have urgency to settle but lesser time to waste.

- Now we have Anerlisa Keroche taking on a Tanzanian boyfriend trying to sublimely send the message to her peers that Kenyan men ain't shit niggres. She is the new mascot of this mindless agenda.

- Women are not special little snowflakes in either the vaginas they possess or the insecurities which burden them. The metaphors in number 8-12 conceptualize the image of women that reduces them to objects. In example 8, reference is made to their sexual desire which the boys went to extinguish. In example 9, women are reduced to a private organ which is also described as tired and beaten up. The example number 10 also makes reference to sexual intercourse which the author states vi allusion that, it reduces the worth of a woman. A mascot is a person or thing that is supposed to bring good luck and example 11 conceptualizes Kenyan women in terms of a mascot. This is used sarcastically in disapproval of the trend where Kenyan women tend to prefer male foreign nationals. And finally, example 12 contrasts Kenyan women to snowflakes and asserts that they are not snowflakes. Snowflakes are attractive and are objects of attraction. The author here is attempting to assert that Kenyan women are not worthy of much effort from men

\subsubsection{Women are Animals}

In the metaphors under analysis women have also been conceptualized in terms of animals. There are several animals, some of which are admired, feared while others are despised. The study was interested in finding out which kind of animals are used in reference to women. are they the productive and useful animals or are they the ones considered as only dependent on humans while having no use. The following animals we noted'

- Ain't no such thing as gold diggers. Women are naturally expensive. So, choose the bitch in your price range and stay in your lane.

- Parasitic slay queens must be eradicated completely. These kinds of ladies deserve a block.

- Start trolling Sheila Mwanyiga, Kui Kamau, Grace Msalame and the likes. These prominent camels will/ must set a good example to other women.

- It is men who have literally fed this monster, this beast, and now it is turning against them, and morphed into an antagonizing and condescending movement of feminist bitches.

- The boy child must be smart, wise and above all prayerful to downplay the perpetual shenanigans of the slay queen who want to suck everything from the boy and at the final end dump the poor boy at the expense of lust and mistrust among the feminist cluster.

The examples 13-17 indicate that women in these Facebook discourses are conceptualized as bitches (female dog), parasites, camel, and beast/monster. The slang bitch is derogative and is usually used to refer to a woman who is belligerent, unreasonable, and malicious and is a control-freak. Parasites are unwelcome insects that are known to feast on their hosts. They give noting in return. A camel is an animal famed for its endurance in terms of its ability to walk long distances with luggage and minimum food and water. Monsters are large, ugly and frightening imaginary creatures while beast refers to a large and dangerous animal. These terms are used to refer to a person who is cruel and wicked. So basically, women are constructed in terms of animals that are dependent and dangerous as well as animals that are hardworking and resilient.

\subsubsection{Women Are Terrorists}

Women have also been conceptualized as terrorists by these Facebook discourses. There have been a number of terrorist attacks in Kenya and so Kenyans are much aware of the sadistic nature of terrorists. Terrorists are mean, cruel and murderous and so a conceptualization of woman as terrorists negates the long-held view that women are tender, caring, and loving. The examples identified from the analysis include;

- Like terrorists, women only understand one language, and that is indifference. To get her, you must be willing to walk away.

- My niggers, this is her strategy. That is how she exerts power in her own narcistic way. There is no difference between her and Adolf Hitler.

- Slay queens are on the run. Please boychild, as your president, be warned, ok! Enjoy your valentine with one who is ready to die for love.

- After my ex made me remove shoes, she had bought me in the CBD, I treat anything given by a woman as a potential death threat except for my relatives.

The identity of women described by these metaphors is that of cruelty, meanness and sadism. Terrorists' main goal is to inflict maximum pain and damage to their victims. Narcissism is a trait when a person is overly self-involved, is vain and is selfish. A narcist only sees himself or herself therefore doesn't care about anyone else. Adolf Hitler is famous for being the mastermind of the Jews genocide that happened in Germany. Those on the run are always criminals seeking to 
hide from the law enforcement authorities. In summary these metaphorical expressions represent the images of women as cruel.

\subsubsection{Women are a Syllabus}

A syllabus outlines the courses or subjects to be undertaken by students pursuing a particular programme or system of education. In the Facebook discourses discussed, the woman's nature, qualities, and attributes are presented as having changed. Men are therefore advised, by this metaphorical association to restudy women and change the way they see women. As argued by Fairclough (1995) identities are never permanent. They change depending on various factors including generational changes. The following examples were identified;

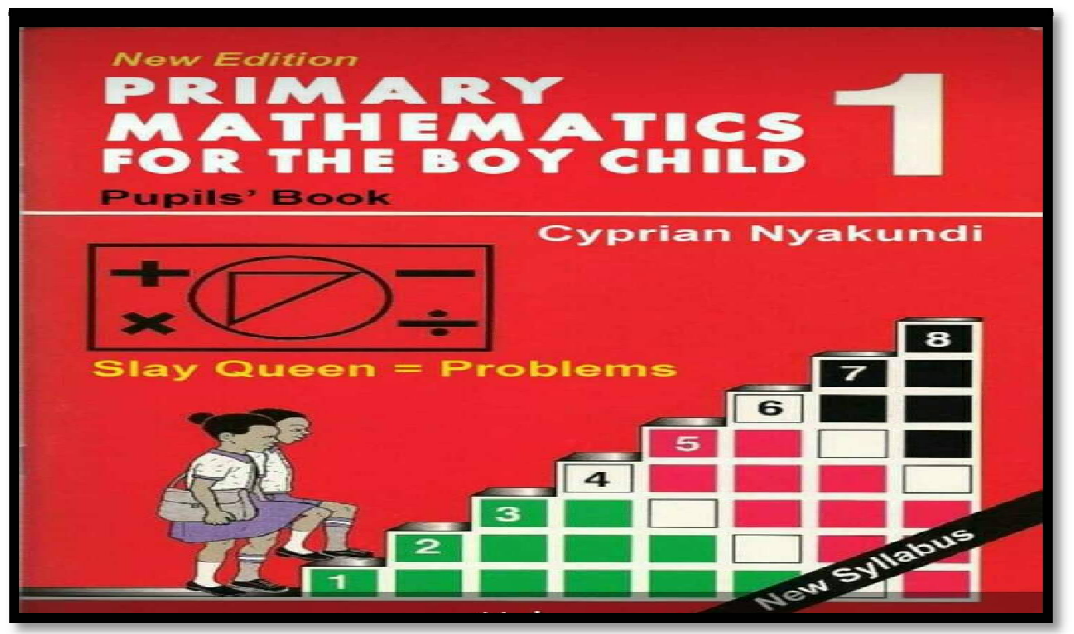

Figure 1

This is modified image of a popular book used in the Kenyan primary education curriculum. in it are several metaphoric items. The first metaphor is the phrase 'new syllabuses. The phrase 'new syllabus' signals a change in the understanding of gender. Traditionally males have dominated the gender debate and with a new syllabus, this is expected to change. The second metaphor which is related to the first is the phrase 'new edition'. Just like 'new syllabus', the metaphor 'new edition' signals a change in the curriculum. The old edition treated women better. All attention focused on the girl child, but the author, Nyakundi, is bringing about a new edition that is calling on the society to also focus on the boy child. The third metaphor in the text above is 'Primary Mathematics for the Boy-child 1: Pupils Book'. Who is the pupil according to this text? The pupil is the general Kenyan population. Nyakundi, the author, has redrawn the syllabus and brought a new edition of how the society ought to treat the boy-child. Nyakundi is calling on the general public to have a rethink on the state of the boy-child in Kenya. The other interesting metaphor worth noting on the text above is the image of the boy and the girl on equal footing. Why is this so? Isn't Nyakundi championing the rights of the boy-child? How come he is suggesting that the boy and the girl are on equal footing? This study argues that the gender Facebook discourse had a general view that the girl child in Kenya is already more empowered than the boy child. What Nyakundi is calling for is fairness and equity in the treatment of both genders. Finally, is a metaphor that equates Slay Queens to problems. The source domain for this metaphor is Mathematics and the target domain is women who are figuratively named as Slay Queens. The metaphor summarizes the reasoning that if one chooses to have a relationship with a woman (Slay-Queen) then they are informed and advised to be ready for problems.

\subsubsection{Women are Mass Media}

Women have always been perceived as talking much more than men. This study found metaphors in the Facebook discourses that likened women to mass media. The conceptualization is that a woman would give little assistance to the family and then make it her business to ensure that everyone hears about it. For instance;

- Ile kuanikwautaanikwabila pegsutafanuiwautajuahujui. She'll buy you a nail cutter and tell the whole world how she had been grooming you naakakutoa far ukiwa sufferer waMungu. She'll invite you for lunch and post on a billboard pale Uhuru Highway na Mombasa Roadof how she has been feeding you since you were an embryo. She'll buy you a vest and go to 'Woman without Limits' and give a testimony of how she has been going to France and Italy frequently to get you expensive designer clothes, the likes of akina 'Gucchi' and 'Giorgio Kimani'. (TemzTemzyTemesi, 2019).

The talkative nature of women here is expressed through metaphors. The metaphors assert that when a woman offers a gift to a man, or even when they offer assistance to the family, they also make sure that every one hears about it.

\subsubsection{Women are Prisoners}

Women have always been described as prisoners of most African cultural practices. The African cultural practices have hindered women's growth in spheres of education, employment opportunities, and career advancement and even in business. The cultural practices that tie woman include Female Genital Mutilation, polygamy, child rearing, and lack of right to own property. However, with much work from most governments and civil society groups, the African woman is 
conceptualized as making advances towards progress. Actually, lately there is a feeling that women are now more empowered than their male counterparts. Examples seen in the study include;

- In an effort to free the girl-child from the shackles of poverty and backwardness, there has been a sustained campaign whose rewards are now paying off. The girl child is now free, confident, independently pursuing her dreams and is no longer the weaker sex. But the downside of this is that the boy child is now the weaker sex and endangered species.

- A lot has been done to give the girl child her voice. Groups and activists come together with many projects that are all about helping the girl child unshackle the chains keeping her down. But the boychild has been left behind. While the girl child is enjoying the freedom and coming out of her shell, the boy child is fighting to be treated better.

The metaphors above give a representation that women were once imprisoned by many factors, including cultural and economic factors. However, with the work of various rights bodies, she is now free: she has gotten rid of the shackles of poverty, she now has a voice, she has taken out the chains that kept her down and she has managed to come out of her shell. All these metaphorical expressions construct women as now free and advanced members of the society.

\subsubsection{Women are Food}

Representation of women in terms of consumables isn't new. In many texts, fictions, songs, poems etc. women have always been compared with food. In the texts analysed, the following metaphors were identified:

- You want soft meat? Marinate it! (Sharon, 2019)

- If you are soft then Kenyan women are not your cup of tea. (Manz, 2018)

- These are the women who have been used by almost every well to do men and dumped. After losing taste, they devise new ways to capture potential sponsors (Wafula, 2018)

The comment in example 26 was used in response to men who complain that Kenyan women are so expensive to keep. The food metaphor of meat was used to state that one must be willing to spend money to get a Kenyan woman. The assertion in example 27 that Kenyan women is not your cup of tea constructs Kenyan women as not likeable, and as people no one enjoys having around. The metaphor in example 28 of Kenyan women 'losing taste' is a food metaphor used to denote overuse/ overstay. When food overstays, it loses taste. The food metaphors used in these discourses construct Kenyan women identities as cruel, and stale.

\section{Discussion}

Not much information exists on the construction of gender identities using internet data in Kenya. However, there is quite a lot of literature with regards to gender identities construction using other media platforms such as newspapers (Muthoni \& Ukaiko, 2016), radio (Omollo, Tchai \& Kiteto, 2015), advertisements (Ochien'g, Otieno \& Mutile), political discourse (Nduva, 2016), and fiction (Mulila-Matei, 2014).

The analysis of metaphor used in Facebook discourse to construct the identity of women revealed that women were basically constructed as commodities, as objects, animals, terrorists, syllabus, mass media, prisoners and food. As commodities, women were compared to items of trade with a price value. They were constructed as depreciating and as movable commodities. This compares to Ahmed's (2018) findings on a study of how some female authors used metaphors to describe women. Ahmed's study which was conducted in Nigeria, women were compared to commodities such as land which can be acquired, they were described as cheap hence affordable to men, and women were regarded as properties owned by men. This is a patriarchal view that is predominant in most African cultures.

The findings also realized that women in these Facebook discourses were represented as objects with no life. For instance, women were compared with fire. Fire can be a good and a bad thing. When there is cold, people warm themselves with fire, we use fire to prepare our meals but on the negative side, when fire is improperly used, then it burns. So, the metaphor of fire was used to represent women as bad and good beings. Parts of the body were used to refer to women. women were represented as capable of being 'used', getting 'tired', being 'banged', they were compared to paints etc. body part terms such as 'pussy' was also constantly used to refer to women. all this was meant to reduce women's status to things with no life hence devaluing them.

The comparison of women with animals also aimed at devaluing women. Hierarchically, animals rank lower than human beings since humans have language, and they reason while animals act on impulse. Kan'gs (2015) and MulilaMatei's (2014) studies also realized that women were metaphorically referred to as animals. In Kang's (2015) study women were compared to small, hunted animals, while in Mulila-Matei's (2014) study, they were compared to a horse. From the two studies, it is evident that metaphorical reference of women in animal terms can both be positive and negative. A comparison of women to horses is positive in the sense that horses are valuable, hardworking animals. A comparison of women to small, hunted animals is negative as it portrays women as victims of men. They are denied activity and are therefore represented as passive. This study revealed that women were metaphorically called camels, bitch, insects, monsters and beasts. A camel is a hardworking animal famous for its endurance. However, in the context of the study, the term was used with negative connotation. 'Bitch' is denotatively a female dog, but connotatively it is a slang word used to refer to a person, usually women, who is malicious and unreasonable. Parasites are usually insects that cause infection to humans. When women are referred to as parasites, they are represented as problematic to men. The terms beasts and monsters are used to refer to women to capture them as wild and dangerous. These terms are used to refer to imaginary animals that are believed to be dangerous though unknown. 
The metaphorical representation of women as terrorists took advantage of Kenyan's experiences with terrorists and terrorism. The main goal of a terrorist is to inflict maximum damage, destruction and cause death. This metaphor constructed women as sadistic beings who have no empathy or sympathy.

The mass media metaphor was aligned along the common belief that women talk more than men. Besides, it is believed that women's money is never seen or felt within the family. When women make a contribution to the family welfare, it is believed that they will have to brag about it. These metaphors represented women as mainly dependants and as people who cannot help one and stay quiet about it.

The syllabus metaphors were used to call for a change in the way the Kenyan society has been treating men and women. For a long time, a lot of focus has been on the empowerment of the girl child and now there is a general feeling among the population that the boy child has been abandoned as is therefore the new endangered gender. The metaphors represent women as not only already too empowered, but also dangerous, and exploitative to the boy child.

The food metaphors used to refer to women are not new. Montashery (2013) argue that people have a tendency of calling their wives or girlfriends using terms such as honey, sweetie etc. such names indicates that women are considered as aesthetic objects to be enjoyed by men. This study witnessed that women were metaphorically referred to as 'meat', they were considered as 'losing taste' and as 'a cup of tea'. The presupposition here is that women are vulnerable to men who are the 'eaters' of food.

\section{Conclusion}

Despite the fact that Facebook is dominated by a generally younger generation, the study concludes that their perception towards women is still old-school. The view that women are vulnerable, passive, and dependent on men is still very much alive. However, there is an emergence of a view that women are now too powerful. They are too powerful that men are beginning to feel threatened. The study witnessed use of a lot of swear words by men in reference to women. this can be attributed to the lack of security and self-esteem that men are beginning to sense as they interact with women.

\section{References}

i. Ali, G., \& Khan, L. (2012). A language and construction of gender: A feminist critique of sms discourse. British Journal of Arts and Social Sciences, 4(2), 342-360.

ii. Bloor, M., \& Bloor, T. (2013). The practice of critical discourse analysis: An introduction. Routledge.

iii. Deignan, A. (2005). A corpus linguistic perspective on the relationship between metonymy and metaphor. Style, 39(1), 72-91.

iv. Group, P. (2007). MIP: A method for identifying metaphorically used words in discourse. Metaphor and Symbol, 22(1), 1-39.

v. Kövecses, Z. (2008). Conceptual metaphor theory: Some criticisms and alternative proposals. Annual review of cognitive linguistics, 6(1), 168-184.

vi. Lakoff, G., \& Johnson, M. (1980). The metaphorical structure of the human conceptual system. Cognitive science, 4(2), 195-208.

vii. Mokamba-Kimuna, B. (2003). Sustained gender stereotyping as shown in Kenyan television commercials, possible effects on the image of women and the way forward (Doctoral Dissertation, University of Nairobi).

viii. Mulila-Matei, A. K. (2014). Discourse, Gender Identity and Gender Power Relations in Fiction: A Critical Discourse Analysis and Systemic Functional Grammar Reading of Wamitila's Unaitwa Nani?. Unpublished doctoral thesis. Kenya: Department of Linguistics and Languages, University of Nairobi.

ix. Munyao, W. L. (2013). Gender issues affecting the girl child in Kenya. Management University of Africa, School of Business and Leadership, Nairobi, Kenya.

x. National Gender and Equality Commission (2015). The Status of the Boy-Child in Kenya: A Report of the Emerging Perception on the Exclusion of the Boy-Child in the Gender Equality Agenda. Nairobi: NGEC.

xi. Newmark, P. (1988). A textbook of translation (Vol. 66). New York: Prentice hall.

xii. Ndungo, C. (1998). The Images of Women as Exemplified in the Gikuyu and Swahili Proverbs. Unpublished PhD Thesis: Kenyatta University. Kenya.

xiii. Nduva, V. M. (2016). Media Portrayal of Women Leaders in Kenya: An Intersection of Female Politicians and Newspaper Narratives (Doctoral dissertation, UNIVERSITY OF NAIROBI).

xiv. Ochieng, R. K., Otieno, T. E., \& Mutile, R. (2013). Gender Stereotyping in Kenyan Media: The Representative Codes of Women in Print Media Advertisements in Kenya.

xv. Turner, M., \& Lakoff, G. (1989). More than cool reason: A field guide to poetic metaphor. Journal of Women $s$ Health.

xvi. Zubair, S. (2007). Silent birds: metaphorical constructions of literacy and gender identity in women's talk. Discourse Studies, 9(6), 766-783. 